\title{
Evolución del concepto de marca personal. Análisis de la repercusión de la prensa en la creación de marca personal en la época victoriana
}

\author{
Marián DE LA Morena TABOAdA \\ Universidad Camilo José Cela \\ mmorena@ucjc.edu
}

\begin{abstract}
Resumen:
En el siglo diecinueve se produjo una rápida expansión de la prensa que coincidió con uno de los periodos más prolíficos en la historia de la narrativa anglosajona. La conexión entre periodismo y literatura se hace patente con la aparición de muchos relatos breves por entregas en los diarios de mayor tirada. Nos encontramos con un grupo de escritores que absorben los postulados de una tradición literaria cuyos orígenes se remontan a las primeras colonias que se establecieron en la costa este de los EE.UU y que provenían en su mayor parte de Reino Unido y de Irlanda. La tradición del relato breve se encuentra profundamente imbricada en el continente americano. Incluso autores de grandes volúmenes como, por ejemplo, Henry James, escribieron también abundantes relatos que encontraron en la prensa su mejor vehículo de transmisión. Los autores se daban a conocer a través de los periódicos llegando a un público muy numeroso que no tenía que hacer mayor desembolso que el de su diario para disfrutar de buena literatura. Por lo tanto la marca no es un concepto moderno originado por el marketing (Pérez Ortega, 2012). Es simplemente la forma de identificar una imagen, un símbolo o incluso una persona como algo valioso, fiable y deseable.
\end{abstract}

Palabras clave: Prensa; marca personal; literatura; periodismo.

\section{Personal Brand: concept and evolution. The influence of the press in the creation of a personal brand in the Victorian era.}

\begin{abstract}
:
The nineteenth century is one of the most prolific periods in the history of the anglo-saxon literature. It is also a moment of rapid expansion for the press and the connection between literature and journalism is enhanced by the publication of an abundant number of short stories in the most important newspapers. These stories are written by a group of writers evolving from a literary tradition which can be traced back to the first colonies established in the eastern coast of the U.S.A whose population came mainly from Britain and Ireland. Short stories are deeply rooted in the American literature and closely related with the press where they found the perfect vehicle for its transmission. Henry James is a good example of this tradition that he combined with the writing of thick volumes. Authors were known through the press and they could reach a much wider audience who could found good literature inside the newspapers they bought. So the concept of personal brand is not a new one created by marketing strategies (Pérez Ortega, 2012). It is simply a way to identify an image, a symbol or a person as something valuable, reliable and desirable.
\end{abstract}

Key Words: press; personal brand; literature and journalism. 


\section{Referencia normalizada:}

De la Morena Taboada, M. (2014): Evolución del concepto de marca personal. Análisis de repercusión de la prensa en la creación de marca personal en la época victoriana. Historia y Comunicación Social. Vol. 19. Núm. Especial Enero. Págs. 393-401.

Sumario: 1. Introducción. 2. Metodología. 3. Los relatos en la prensa. 3.1 Literatos y periodistas. 4. Tipología de los relatos: influencia de la narrativa de fantasmas.. 4.1La importancia de la sociedad para el estudio psicológico. 4.2 Relatos: The Turn of the Screw y The Wind in the Rosebush. 5. Análisis del concepto de marca personal en ambos autores. 5.1 Biografía. 5.2 Entorno. 6. Conclusiones. 7. Referencias Bibliográfícas

\section{Introducción}

En este artículo vamos a analizar la vinculación histórica entre literatura y periodismo y si esta pudiera responder a un criterio de creación de marca personal que encontrara en la prensa un eficiente método de divulgación.

Una de la autoras estudiadas, Mary Wilkins Freeman, gozó de mucho prestigio y reconocimiento llegando a recibir el William Deans Howells Award en 1925, uno de los más prestigiosos y reconocidos galardones literarios del momento. En la actualidad y al final de sus días fue prácticamente olvidada. Se plantea la condición femenina como variable a tener en cuenta para la pérdida de reconocimiento, también el hecho de que su vida transcurriera siempre en el mismo entorno puritano de Nueva Inglaterra frente al cosmopolitismo de el otro autor analizado, Henry James, cuya fama ha perdurado en el tiempo, llegando a considerarse entre los grandes maestros de la literatura universal. ¿Qué variables influyen en la perdurabilidad de la marca de autor?

\section{Metodología}

Para llevar a cabo el estudio se han seleccionado dos historias de estos autores que fueron publicadas en prensa por entregas y que además nos permiten profundizar en el estilo de ambos.

Las historias seleccionadas son "The Turn of the Screw" de Henry James utilizando la versión revisada y publicada en 1992 por Oxford University Press y "The Wind in the Rosebush"de Mary Wilkins Freeman utilizando la versión publicada por la Academia de Editores de Chicago en 1986. En ambas aparece la figura femenina como protagonista principal y también se trata del tema de los abusos en la infancia pues son niños los que sufren las apariciones o las consecuencias de las mismas. Este análisis nos permite corroborar elementos comunes en ambos autores así como algunas diferencias. Si bien la narrativa de fantasmas adquirió mucha relevancia en 
el momento, en estos dos relatos coinciden también otras variables que hacen más interesante el estudio de la repercusión de la obra de los dos autores.

\section{Los relatos en la prensa}

Una cuestión muy interesante y característica de la etapa victoriana es la estrecha relación entre literatura y periodismo. Podría resultar paradójico que una narrativa de ficción en la que abunda la temática sobrenatural tuviera conexiones con el ámbito periodístico donde se impone la objetividad de los hechos. Para entender esta implicación es necesario hacer un breve repaso a la presencia de la literatura en el periódico anglosajón que se remonta a la época de Charles Dickens al que, sin duda, podemos considerar precursor de esta conexión. Como líder literario Dickens no tuvo parangón entre los hombres y mujeres de letras de su época y, como dice Thomas Hay Sweet Escott ya en el año 1912 en su libro Literature and Journalism (Literatura y Periodismo), fue uno de los principales colaboradores de diarios y revistas donde publicó la mayor parte de su extensa obra. Además, durante más de un cuarto de siglo, formó a un amplio grupo de periodistas que colaboraban y, en ocasiones, escribían para él en lo que puede considerarse inicio de la denostada práctica del escribano de relatos para otras plumas de más reconocido postín. Empezó a impartir sus cursos de edición en la revista Bentley's Miscellany en 1837, continuó en 1846 en el Daily News y en 1850 en Household Words. Realmente no cesó en su labor supervisora de ediciones hasta que falleció en 1870. Parafraseando a Sweet Scott Dickens no sólo poseía, sino que también cultivaba con intenso trabajo, un instinto que detectaba los elementos de excelencia en la producción de textos que llegaban a su mesa editorial. Como escritor tenía predilección por la literatura y su influencia será decisiva para dar a conocer a jóvenes escritores que inician su andadura literaria en el día a día del periódico (Sweet Scott, 1912).

\subsection{Literatos y periodistas}

El tipo de periodista formado como literato fue el resultado de las fuerzas e intereses que operaban en los lectores y escritores del momento y que respondían a unos gustos y maneras que hoy han desaparecido. El periodismo victoriano no hizo sino seguir el ejemplo de la literatura victoriana (Sweet Escott, 1912). Tiempo después de que surgiera la prensa barata, asequible para casi todos, los mejores periódicos mantenían una afinidad mucho más estrecha con la prosa inglesa del siglo dieciocho que con el modelo francés que había sido popularizado con anterioridad por el periódico Vogue Courier. La cultura de las clases educadas seguía siendo literaria y se disfrutaba reconociendo estos aspectos en los periódicos que adquirían a diario. Haciendo un repaso de las opiniones de los investigadores de la época nos encontramos con lo que Charles A. Dana refleja en su libro The Art of Newspaper Making (El Arte de Hacer Periódicos) ya en 1895 como una mirada maravillada hacia el progreso en la prensa de la época. La revolución en la técnicas de impresión posibi- 
litó la producción de miles de ejemplares en muy poco tiempo para los estándares de la época y así contribuyó a una amplísima difusión de la narrativa de los escritores que surgían a la sombra de este nuevo "milagro divulgativo" (Dana, 1895). A esto podemos añadir una característica de la civilización norteamericana que de nuevo Dana nos señala en su libro, la multiplicidad de periódicos en los EE.UU que excede con amplitud a cualquiera de los publicados en ningún otro país con lo que las posibilidades de llegar a un gran número de lectores multiplicaba el atractivo de la prensa para los literatos. Como conclusión a este punto sirva de orgullosa reflexión para los escritores repasar estos datos sobre los inicios de la prensa y su estrecha relación con la literatura, pues fueron maestros de la talla de Dickens los que establecieron unas bases creadoras de altísimo nivel, que respondían a unas demandas sociales y que, a la vez, contribuían de manera inequívoca a incrementar los niveles culturales de la sociedad a la que servían.

\section{Tipología de los relatos. Influencia de la narrativa de fantasmas}

La época victoriana supuso también un periodo de esplendor para la narrativa de fantasmas en el mundo anglosajón como lo demuestran las numerosas obras escritas por los autores más relevantes del momento como Washington Irving, Nathaniel Hawthorne, Edgard Allan Poe y por supuesto Charles Dickens. Las razones de dicho florecer pueden encontrarse en una fructífera economía impulsada por los avances científicos y tecnológicos que contrastaba con un pasado mucho más tenebroso e infeliz. Durante todo el siglo diecinueve las historias de fantasmas convivieron con la fascinación victoriana por la muerte y lo que sucedía después de ésta.

\subsection{Importancia de la sociedad para el estudio psicológico}

La espiritualidad moderna fue un regalo de Estados Unidos para el mundo occidental (Lustig, 1994). En 1885 se fundó la Society for Psychical Research para investigar actividades parapsicológicas desde una perspectiva que quería acercarse a la ciencia. Es la organización de estudios psicológicos más antigua de los Estados Unidos. Una de las figuras determinantes para este acercamiento fue el psicólogo William James, considerado padre de la psicología moderna y hermano de Henry James. Fue presidente de la sociedad de 1894 a 1897 y trató de crear uniones entre la nueva psicología que estaba desarrollando y la necesidad de estudiar los fenómenos psíquicos (Bantha, 1972). Henry James reconoció las posibilidades latentes en el cuento de miedo y practicó durante una década con el género entre 1865 y 1876. En la última década del siglo se sintió preparado para retomar de nuevo este género perfilándolo como un modo personal de expresión y un procedimiento eficaz para descubrir cosas nuevas (Bantha, 1972). La búsqueda de nuevas formas de expresión de Mary Wilkins Freeman dio forma al desarrollo de sus relatos cortos, llevándola primero al misticismo y después a lo sobrenatural. Expresa una fascinación constante por la naturaleza 
haciendo uso de conexiones místicas que conducen a una exploración no sólo del temor a los fantasmas sino de la identidad de los miedos. (Bendixen, 1986).

En este contexto socio-cultural escriben ambos sus relatos que aparecerían publicados en la prensa con la común intención de alcanzar notoriedad y prestigio.

4.2 Relatos the turn of the screw and the wind in the rosebush

La temática de fantasmas y apariciones es común a los dos. The Turn of the Screw "Otra vuelta de tuerca" de Henry James relata la historia de dos hermanos, un niño y una niña al cuidado de una institutriz en una casa señorial inglesa con un padre permanentemente ausente. La institutriz cree ver las apariciones de dos antiguos criados fallecidos y que de alguna manera se han apropiado de la personalidad de los niños de los que se sospecha abusaron sexualmente. The Wind in the Rosebush "El viento que agita el rosal" de Wilkins Freeman, cuenta la historia de una mujer, Rebecca, que quiere quedarse con la custodia de su sobrina, hija de su hermana muerta, cuyo padre acaba de fallecer y al cuidado de su madrastra. La presencia del fantasma se revela al final de la historia dejando al lector que concluya que la niña también ha muerto víctima de los abusos de la madrastra y que está "encarnada" en el rosal, "rosebush", que se encuentra a la entrada de la casa. No hay mansión victoriana en el relato de Freeman aunque la casa juega un papel importante en la historia, al igual que Bly en la de James. Parece como si todo hubiera sido modelado a escala inferior en The Wind in the Rosebush lo que puede conectar con las diferentes circunstancias y enfoques personales con los que se escribieron ambas historias. Otra conexión muy interesante que se puede resaltar es el hecho de que los niños son objeto de abusos por parte de mujeres en su egoísta búsqueda de la maternidad. Bendixen sugiere que los fantasmas presentes en la ficción de Freeman son los mismos que se aparecían en la Nueva Inglaterra del siglo diecinueve, los fantasmas de la ambición frustrada, el deseo reprimido y el amor rechazado (1986). Por otra parte es necesario enlazar con la cuestión de narrar y ver y con el fantasma en ambas historias. Éste es, por definición, el que puede ver sin ser visto, es decir, el fantasma nos determina siempre un efecto visera que parece interactuar con el lector que es, a su vez, el que puede ver sin ser visto. De este modo se espectraliza al lector convirtiéndolo en un dentro-del-relato esencial. ¿Qué decisión le cabe al lector convertido en fantasma sino vagar y hacer errabunda la propia historia que lee? Ver y narrar se relacionan aquí profundamente a partir de la idea presencial del fantasma. Ambas historias están construidas para realzar la importancia del lector que se convierte también en protagonista de ambas, claro objetivo de atracción y de permanencia en la mente de su público.

\section{Análisis del concepto de marca personal en ambos autores}

El concepto de marca personal es relativamente nuevo. Podemos trazar sus orígenes en el año 1997 en el que Tom Peters publica un artículo titulado The Brand Called 
You (Peters, 1997) en el que afirma que la única manera de diferenciarnos en un mercado competitivo es tratar de identificarnos y diferenciarnos de manera parecida a la que las empresas venden sus productos.

Este concepto no se acuñaba como tal en el momento en que nuestros autores escriben sus relatos pero, como afirma Pérez Ortega, no es una idea moderna producto del marketing (2011). Ambos autores escriben sobre temática que interesaba en el momento, tratan de convertir a los lectores en parte activa de sus relatos y utilizan los mismos vehículos para obtener una máxima difusión de su obra, en este caso la prensa. Tratan temáticas de plena actualidad como hemos visto. También comparten el interés por alcanzar reconocimiento, siendo éste uno de los elementos que caracterizan el concepto de marca personal. Podemos decir, por tanto, que ambos comparten el desarrollo de un proceso que tiene como objetivo la identificación de aquello que resulta valioso, fiable y útil.

Así pues si ambos comparten los principales elementos que definen el desarrollo de la marca personal tenemos que añadir al análisis otras variables que determinen la perdurabilidad de la misma en el tiempo.

\subsection{Biografía}

Henry James nació en Greenwich Village en 1843, Nueva York fue la ciudad de su infancia. Los cambios que tuvieron lugar en esta ciudad representaron para él el paso de la era victoriana de su infancia al mundo moderno de sus años adultos. Fue un testigo privilegiado de la decadencia y final de una era y un cronista reconocido de cómo se estaba transformando la sociedad tanto en Estados Unidos como en Europa (Kaplan, 1992). Mary Wilkins Freeman nació en 1852 en Randolph, Massachusetts, que por aquel entonces era un pueblo rural cerca de Boston en el seno de una familia de congregacionalistas incondicionales. Podemos decir que se crió siguiendo las tradiciones típicas de los pueblos de Nueva Inglaterra. No tardó en desarrollar lo que Foster califica como "conciencia puritana de Nueva Inglaterra" con la convicción de que no debería nunca ser dependiente de otras personas. Henry James representa a la aristocracia estadounidense mientras que Mary Wilkins Freeman fue una mujer sencilla que nunca abandonó su país para explorar y comprender el modo de vida europeo, que para Henry James constituía las raíces del pensamiento estadounidense (Reichardt, 1992). Los primeros años de la infancia de Mary estuvieron llenos de mensajes restrictivos relacionados con las costumbres religiosas. Nunca olvidaría el énfasis de su padre en el deber sagrado de reunirse en la iglesia, su crítica a los juegos de cartas, el baile y la bebida y su insistencia en los "diez mandamientos" como piedra angular del modo de vida cristiano (Ender, 1995). Henry James recibió una visión completamente diferente de la religión y su padre concedía a todos los miembros de la familia total libertad a la hora de escoger el destino vital que consideraran mejor o si fuera el caso, no escoger ninguno. (Álvarez Calleja, 2000). 


\subsection{Entorno}

La tradición de lo sobrenatural y el relato breve en la literatura estadounidense tiene unas profundas raíces que se remontan a una época considerada como el origen de una nueva escuela de escritores que poco a poco se fueron diferenciando del mecenazgo británico (Mc Call, 1999). Washington Irving (1783-1859) fue el eje central de este grupo que se desarrolló en Nueva York, por aquel entonces una pequeña ciudad en expansión en la desembocadura del rio Hudson. Su desarrollo profesional aunó un interés por la prensa y la literatura y, al igual que Henry James, recorrió varios países de Europa donde vivió largas temporadas llegando a ocupar el cargo de embajador de los Estados Unidos en España. Se le considera el primer escritor norteamericano en alcanzar la fama y fue mentor de otros grandes escritores como Nathaniel Hawthorne o Edgard Allan Poe.(Scarborough, 2001).

La internacionalización es una característica que comparte con otros escritores de su entorno cuya fama ha perdurado en el tiempo y no es compartida por Mary Wilkins Freeman, que, como se ha señalado, nunca viajó fuera de las fronteras de su estado de nacimiento. Se propone por tanto la variable internacionalidad como elemento diferenciador a la hora de obtener una marca personal que perdure en el tiempo.

\section{Conclusiones}

El liderazgo literario que Charles Dickens ejerció desde Gran Bretaña fue sin duda un elemento determinante para la estrecha relación entre literatura y periodismo en la época victoriana que se ha constatado en este estudio. Su figura alcanzó un prestigio social muy elevado a ambos lados del Atlántico. Los lectores querían que los periódicos y revistas que compraban fueran un reflejo fiel de la realidad que imperaba en el momento. Parece que la prensa contribuyó a divulgar la cultura literaria porque los lectores así lo querían. La llegada de la prensa a una audiencia cada vez más grande parece haber contribuido a la aparición de nuevos escritores que pueden darse a conocer con más facilidad. Entre ellos se encuentran las dos figuras analizadas, Mary Wilkins Freeman que publica su primer relato en una revista, Harper's Bazar, y poco a poco va construyéndose una marca personal hasta llegar a obtener un prestigioso galardón literario. Pero esto no fue suficiente para garantizar su perdurabilidad. Estudiar su vida y entorno social y compararlo con el de Henry James revela muchas similitudes y grandes contrastes, entre los que destacarían el puritanismo familiar del entorno de Mary con una estricta observancia religiosa, frente a la total libertad con la creció Henry James. Un siguiente aspecto lo constituye la internacionalización de éste último que no se produjo en la autora. En cuanto a las similitudes destacamos en ambos el cultivo del género narrativo de fantasmas. Hemos visto como la gran mayoría de autores lo cultivaron y las razones podrían ser sociológicas y culturales como reacción a un mundo en constante progreso y mecanización. Los fantasmas se 
incorporan a la vida cotidiana y son objeto de interpretación por parte de críticos y lectores. Esta narrativa parece querer dar respuesta a una demanda social que busca en el más allá una conexión con un mundo pasado que desaparece a la misma velocidad que se incorporan los nuevos avances tecnológicos. El fantasma podría ser el espectro de un estilo de vida que está siendo superado. Además de la presencia del fantasma los dos coinciden al mostrar niños que sufren abusos en una sociedad que critican. Todo esto pudo ser determinante en la fama que ambos autores gozaron en vida, compartir una visión del mundo comprometida con lo que estaba sucediendo, pero no fue suficiente para garantizar la perdurabilidad de Mary Wilkins Freeman que, a pesar de ser parte de este grupo de escritores, ha perdido su reconocimiento con el paso del tiempo.

\section{Bibliografía}

ÁLVAREZ CALLEJA, M.A (2000). Henry James' fiction as a turning point between conventions and Modernity. En Do Esplendor na relva. Elites e cultura comum de expressao inglesa. Lisboa: E.Cosmos 473-80

BANTHA, M. (1972). Henry James and the occult: The Great Extension. London: Indiana University Press.

BENDIXEN, A. (1986). The Wind in the Rosebush and other Stories of the Supernatural by Mary Wilkins Freeman. Chicago: Academy Chicago Publishers.

DANA, C. A. (1895). The Art of Newspaper Making. New York: D. Appleton and Company

ENDER, E. (1995). Sexing the Mind: Nineteenth Century Fiction of Histeria. Ithaca: Cornell University Press

KAPLAN, F. (1992). Henry James and the Imagination of Genious: A Biography. New York: William Morrow and Company Inc.

LUSTIG, T (1994). Henry James and the Ghostly. Cambridge: Cambridge University Press

MC. CALL, D. (1999). Citizens of Somewhere Else. Nathaniel Hawthorne and Henry James. Ithaca: Cornell University Press

PÉREZ ORTEGA, A. (2012). Marca Personal: Cómo convertirse en la opción preferente. Madrid: ESIC editorial.

PETERS, T. (1997). La marca que llama. Fast Company, 10 (10)

REICHARDT, M.R. (1992). A Web of Relationships. Jackson: University press of Mississippi

SCARBOROUGH, D. (2001). The Supernatural in Modern English Fiction. New Jersey: Lethe Pres 


\section{La autora}

Marián de la Morena Taboada es profesora de la Universidad Camilo José Cela desde el año 2000. Licenciada en Filología inglesa por la UCM y Máster en Dirección de Marketing y Gestión Comercial por ESIC es doctora acreditada en Ciencias Sociales y de la Educación. Ejerce como docente en las Facultades de Ciencias de la Comunicación y Ciencias Sociales y de la Educación. Es profesora invitada de las universidades Plantijn, Artevelde y Erasmus Hogeschool de Bélgica donde ha impartido seminarios sobre marca personal y redes sociales. Su experiencia profesional se ha desarrollado en ámbitos internacionales que incluyen la embajada de los EE.UU. en Madrid y el Departamento de Atención al cliente del Deutsche Bank en Wiesbaden, Alemania. Ha participado en numerosos congresos nacionales e internacionales donde ha presentado comunicaciones sobre redes sociales, marca personal, motivación y estrategias de aprendizaje. 